\title{
Innovation Capacity Building
}

An approach to maintaining balance between exploration and exploitation in organizational learning

Brix, Jacob

Published in:

Learning Organization

DOI (link to publication from Publisher):

10.1108/TLO-08-2018-0143

Creative Commons License

CC BY 4.0

Publication date:

2019

Document Version

Publisher's PDF, also known as Version of record

Link to publication from Aalborg University

Citation for published version (APA):

Brix, J. (2019). Innovation Capacity Building: An approach to maintaining balance between exploration and exploitation in organizational learning . Learning Organization, 26(1), 12-26. https://doi.org/10.1108/TLO-082018-0143

\section{General rights}

Copyright and moral rights for the publications made accessible in the public portal are retained by the authors and/or other copyright owners and it is a condition of accessing publications that users recognise and abide by the legal requirements associated with these rights.

- Users may download and print one copy of any publication from the public portal for the purpose of private study or research.

- You may not further distribute the material or use it for any profit-making activity or commercial gain

- You may freely distribute the URL identifying the publication in the public portal - 


\section{emeraldinsight}

\section{The Learning Organization}

Innovation capacity building: An approach to maintaining balance between

exploration and exploitation in organizational learning

Jacob Brix,

\section{Article information:}

To cite this document:

Jacob Brix, (2018) "Innovation capacity building: An approach to maintaining balance between

exploration and exploitation in organizational learning", The Learning Organization, https://

doi.org/10.1108/TLO-08-2018-0143

Permanent link to this document:

https://doi.org/10.1108/TLO-08-2018-0143

Downloaded on: 04 December 2018, At: 05:38 (PT)

References: this document contains references to 42 other documents.

Access to this document was granted through an Emerald subscription provided by All users group

\section{For Authors}

If you would like to write for this, or any other Emerald publication, then please use our Emerald for Authors service information about how to choose which publication to write for and submission guidelines are available for all. Please visit www. emeraldinsight. com/ authors for more information.

\section{About Emerald www.emeraldinsight.com}

Emerald is a global publisher linking research and practice to the benefit of society. The company manages a portfolio of more than 290 journals and over 2,350 books and book series volumes, as well as providing an extensive range of online products and additional customer resources and services.

Emerald is both COUNTER 4 and TRANSFER compliant. The organization is a partner of the Committee on Publication Ethics (COPE) and also works with Portico and the LOCKSS initiative for digital archive preservation.

*Related content and download information correct at time of download. 


\title{
Innovation capacity building An approach to maintaining balance between exploration and exploitation in organizational learning
}

\author{
Jacob Brix \\ Department of Learning and Philosophy, Aalborg University, \\ Aalborg Oe, Denmark
}

Innovation capacity building

\begin{abstract}
Purpose - The purpose of this paper is to propose how a bottom-up creation of an ambidextrous organization can be enabled. By integrating research on "contextual ambidexterity" and "individual and organizational capacity building", an "innovation capacity building" framework is conceptualized that suggests how balance between exploration and exploitation can be maintained.

Design/methodology/approach - The study is conceptual. As no data are utilized, focus is on discussing the links between the two theoretical perspectives and the advantages of the proposed innovation capacity building framework.

Findings - The innovation capacity building framework discusses the influence, both positive and negative, of the local organizational context for ambidexterity, and the interactions required such as feedback between the management team and the employees so they together can build an ambidextrous working culture. A culture in which it is the individual employee that is responsible for switching between activities related to exploration and exploitation and where the management team empowers the employees to do so.

Originality/value - This study focuses on contextual ambidexterity and how contextual ambidexterity can be implemented as a way of working in contemporary organizations. The originality lies in the proposed framework and in the dedicated focus on "how" ambidexterity can be implemented in organizations.
\end{abstract}

Keywords Organizational learning, Ambidexterity, Innovation management, Exploration and Exploitation, Capacity building, Contextual ambidexterity

Paper type Conceptual paper

Demographic changes, economic trends, and new legislation, for example, shape the future. Whether and how an organization responds to these signals determines its influence on changes that ultimately occur (Honadle, 1981, p. 577).

\section{Introduction}

Multiple studies establish that optimal performance levels can be found in organizations that are able to maintain an appropriate balance between activities related to exploration

(c) Jacob Brix. Creative Commons Attribution (CC_BY) 4.0 licence. The funding utilized to finance the open access version of this paper stems from the author's talent management program in which he is enrolled at Aalborg University's Faculty of Social Sciences.

The author wishes to thank his colleague and Head of Research, Professor Hanne Kathrine Krogstrup, for excellent sparring and feedback on earlier versions of this manuscript. The same gratitude goes to Professor Richard M. Burton at the Fuqua School of Business at Duke University for valuable feedback. Kudos is also given to the reviewers and especially the special issue editors, Dr Nhien Nguyen and Professor George P. Huber for quick, precise and to-the-point feedback in the review process.

Received 10 September 2018 Revised 9 October 2018 31 October 2018 Accepted 1 November 2018 
and exploitation. Such organizations are often referred to as being "ambidextrous", and research establishes that identifying and maintaining this delicate balance is possible in both private organizations (Benner and Tushman, 2003; Uotila et al., 2009; Hoang and Rothaermel, 2010) and in public organizations (Choi and Chandler, 2015; Brix, 2017; Palm and Lilja, 2017). Building an ambidextrous organization is however not an easy task. This is argued because the pay-offs related to the counterintuitive activities of exploration and exploitation are well established:

- If organizations overemphasize exploitation, they reduce learning new skills and might become captive to outdated competencies, technology, etc. that might depress long-term performance.

- If organizations overemphasize exploration, they risk utilizing scarce resources and getting unsatisfactory pay-back, thus depressing short term benefits (March, 1991; Hoang and Rothaermel, 2010).

Moving from exploration to exploitation is difficult because the organization and its members have the most experience and knowledge about how to navigate in their current situation, which most often is characterized as being either exploitative or explorative (March, 1991; Gaim and Wåhlin, 2016). A potential cause of this this either/or problem is that "doing things better" (exploitation) leads to fewer struggles and less opposition from organizational members while "doing better things" (exploration) attracts much more attention and resistance. This even though exploration is necessary to adequately adapt to significantly changing environments and hence future survival (Huber, 2004; Wei et al., 2014).

Two different views relate to the "ambidexterity dilemma", namely, the dilemma between exploration and exploitation. One argument is, that that exploratory and exploitative learning are incompatible because they compete for the same resources and this argument represents the differentiation view (Smith and Tushman, 2005). The other argument suggests that there are complementary benefits between the two approaches to learning and this argument represents the integration view (Gibson and Birkinshaw, 2004). The problem in question is hence how the ambidexterity dilemma is approached. One stream of literature suggests that "structural ambidexterity" is the solution. Structural ambidexterity refers to the decision of separating the work with exploration and exploitation into different departments (Andriopoulos and Lewis, 2009). Another approach to the dilemma is "sequential ambidexterity", which refers to the process of transitioning from one "state" to "another", e.g. by implementing change management programs (O'Reilly and Tushman, 2013; Raisch et al., 2009). Both of these streams of literature represents the differentiation view. Even though existing research has provided many insights about the advantages and challenges of exploration and exploitation, the understanding of "how" an organization can leverage ambidexterity is still low (Wei et al., 2014; Choi and Chandler, 2015). According to Raisch et al. (2009), a fundamental problem is the following:

Ambidexterity research usually describes organizational mechanisms to enable ambidexterity, such as formal structures or lateral coordination mechanisms. Conversely, some studies indicate that ambidexterity is rooted in an individual's ability to explore and exploit. Organizational mechanisms may be required to enable ambidexterity at the individual level, and ambidextrous individuals may be vital to the usefulness of organizational mechanism. There is, therefore, a need for theories that capture ambidexterity across multiple levels of analysis. (Raisch et al., 2009, p. 686).

As mentioned above, the implementation of ambidexterity has so far been mainly concerned with structural ambidexterity and sequential ambidexterity, but more recently scholars have started to emphasize the importance of bottom-up approaches to solve the 
ambidexterity dilemma, namely, “contextual ambidexterity” (O’Reilly and Tushman, 2013; De Clercq et al., 2013; Wang and Rafiq, 2014). Contextual ambidexterity is part of the integration view, and it refers to: the behavioral capacity to simultaneously demonstrate alignment and adaptability across an entire business unit (Gibson and Birkinshaw, 2004, p. 209). This means that the ambidexterity dilemma can be solved by understanding the behaviors of the management and the employees and their interactions related to exploration and exploitation in their contextual work environment. As contextual ambidexterity is a relatively new theoretical construct, Gibson and Birkinshaw (2004), Simsek et al. (2009), Güttel and Konlechner (2009), Wang and Rafiq (2014) and Havermans et al. (2015) call for research on how contextual ambidexterity can be achieved by involving the managers and employees, and under which conditions this involvement may be successful.

The purpose of this study is to respond to this call by discussing how the literature on individual and organizational capacity building (Farazmand, 2004; Ku and Yuen-Tsang, 2013; Krogstrup, 2016) can be used as a theoretical framing for building and maintaining contextual ambidexterity in established organizations. Capacity building in this regard is defined as activities that strengthen the knowledge, abilities, skills and behavior of individuals, and improve institutional structure and processes, so that the organization can efficiently meet its goals in a sustainable way (Ku and Yuen-Tsang, 2013, p. 1). Based on this theoretical integration, an 'innovation capacity building' framework is conceptualized. The main contribution of the study is this framework that proposes how individual and organizational capacity building processes can be used by managers to empower the employees to make appropriate judgements between exploration and exploitation to reach both their own individual goals and to work towards realizing the organization's intended strategy. This bottom-up approach and strong focus on the manager-employee interaction resonates with the study of the successful implementation practices by Havermans et al. (2015, p. 194), which concludes that:

Our results suggest that contextual ambidexterity can emerge in interaction between leaders and their team members and as a result of their dynamic interpretations of the environment and efforts to respond to perceived environmental changes.

By integrating a capacity building perspective into the ambidexterity literature, and hence into the study of organizational learning, this paper offers a dual level understanding of how the top management team can build the capacity of the organization to foster the context for ambidexterity (organizational capacity building) while simultaneously empowering the individual employees and building their capacities to process both explorative and exploitative learning activities (individual capacity building) (Farazmand, 2004). The concern addressed in the study thus does not pertain to "why" maintaining balance between exploration and exploitation is important but rather it addresses the issues of "how" an organization and its members can build their capacities to survive and prosper based on the resources that they have available (Sirmon et al., 2011; Gaim and Wåhlin, 2016). A step back is thus taken to discuss the mechanisms that lead to the ability of an organization and its members to remain relevant in their context by building their capacities to act ambidextrously (Huber, 2004).

The study proceeds as follows. First, the Section 2 introduces the literature on contextual ambidexterity and the literature on individual and organizational capacity building. After having introduced the theoretical background, Section 3 presents a synthesis of the two streams of literature in which the "innovation capacity building" framework is proposed. Finally, the conclusions of the study are presented in Section 4. 


\section{TLO}

\section{Theoretical background}

The theoretical background is divided into two sub sections. First, the literature on contextual ambidexterity is reviewed to frame the context in which the capacity building process is to take place. Afterwards, the literature on individual and organizational capacity building is reviewed to clarify and synthesize the process and content of how capacity building come about, so it can be introduced into the organizational arena of contextual ambidexterity.

\subsection{Contextual ambidexterity}

Contextual ambidexterity is - as stated above - defined as "the behavioral capacity to simultaneously demonstrate alignment and adaptability across an entire business unit" (Gibson and Birkinshaw, 2004, p. 209). Contextual ambidexterity is therefore focused primarily on behavioral and social means to integrate exploration and exploitation as a balancing act compared to structural and sequential ambidexterity (Andriopoulos and Lewis, 2009; O'Reilly and Tushman, 2013). As remainder, structural ambidexterity refers to the division of work pertaining to exploration and exploitation in different organizational units, which can lead to issues of integration in the parent organization (Andriopoulos and Lewis, 2009; O'Connor et al., 2018). Sequential ambidexterity refers to the implementation of (larger) organizational change-management projects over time (O'Reilly and Tushman, 2013).

Based on Gibson and Birkinshaw's (2004) work on contextual ambidexterity, Andriopoulos and Lewis (2009) argue that supportive social processes (e.g. socialization and recognition practices), culture and interpersonal relations help actors throughout the firm think and act ambidextrously (Andriopoulos and Lewis, 2009, p. 698). Hence, contextual ambidexterity is a multilevel phenomenon, as are many other organizational learning theories (Crossan et al., 1999; Brix, 2017). Contextual ambidexterity entails a minimum of two units of analysis the organization in which the ambidexterity dilemma is manifested and its influence on the individual employees' judgements on how to best divide their work between the conflicting requirements of exploration and exploitation (Raisch et al., 2009; Wang and Rafiq, 2014; Havermans et al., 2015).

The organizational context is required to be based on: an interaction of stretch, discipline and trust (Gibson and Birkinshaw, 2004, p. 214) if the employees' individual "switching" between tasks is to be promoted and effectuated (Raisch et al., 2009). On the individual level, the switching between exploration and exploitation tasks can take the form of sequential ambidexterity where even short phases of exploration (minutes or hours) become part of the routine work with the daily operations (Raisch et al., 2009).

2.1.1 Advantages related to contextual ambidexterity. O'Reilly and Tushman(2013) conclude in their seminal work that ambidexterity, no matter whether it is structural, sequential or contextual, is positively associated with improved business unit performance. Gibson and Birkinshaw (2004) stress that contextual ambidexterity enables the parallel processing of different business processes. This especially concerns organizations doing business in dynamic environments that are often left with no choice but to consolidate existing businesses while concurrently identifying and elaborating new opportunities. Simsek et al. (2009) and Wang and Rafiq (2014) point out that contextual ambidexterity represents a superior approach to organizational learning compared to the two other types of ambidexterity. One argument supporting this claim is as follows:

Contextual ambidexterity epitomizes the development of an entire firm geared towards the integration of exploration and exploitation through a process of organizational learning, thus avoiding the coordination costs incurred due to structural separation and the transition costs due to temporal separation (Wang and Rafiq, 2014, p. 60). 
Another argument related to this claim is, according to O'Reilly and Tushman (2013), that contextual ambidexterity enables a high degree of efficiency in existing work flows, as the individual employee can decide to break out of an existing routine and explore if new variations of the work flow will make their job more efficient. This "breaking out" is frequently labeled 'meta-routines' (Güttel and Konlechner, 2009; Simsek et al., 2009). Another advantage of contextual ambidexterity is, according to O'Reilly and Tushman(2013) that it also leads to more openness towards changes and increased responsiveness towards new opportunities in the business units. The argument in this regard is based on the employees' practical experiences and the building of competencies in relation to both exploration and exploitation. This consequently enables the employees to contribute and perform in both domains (Simsek et al., 2009; Brix and Peters, 2015). Increase in performance both concerning exploration and exploitation is also claimed to lead to a better company reputation and prestige (Cegarra-Navarro and Dewhurst, 2007). Finally, it is argued that the successful implementation of contextual ambidexterity is seen as a source of competitive advantage, since such parallel processing of conflicting demands represents a "valuable, rare and costly to imitate" resource (Simsek et al., 2009).

2.1.2 Disadvantages and challenges related to contextual ambidexterity. The disadvantages and challenges pertaining to contextual ambidexterity are issues of implementation. Yang and Atuahene-Gima (2007, p. 6) emphasize that significant resources and managerial efforts need to be invested up front to develop the superior capabilities for reining the two opposing forces (...). Following their argument, researchers state that successful implementation requires the "mitigation of resource conflicts", "suitable leadership styles", "supportive incentive structures" and, last but not least, knowledge about the generative mechanisms that enable the appropriate judgement of the individual employees being responsible for the switching (Wang and Rafiq, 2014; De Clercq et al., 2013; O'Cass et al., 2014; Havermans et al., 2015). O'Cass et al. (2014) state that a poor strategy implementation at the operational level reduces the expected outcomes of deploying ambidexterity because the managerial level takes for granted that the employees' abilities to switch between work tasks already exist (Brix's (2015) multiple case study on failed innovation projects for concrete examples). What is less clear is the role of the management team and the leaders supporting contextual ambidexterity (O'Reilly and Tushman, 2013). Finally, a key issue is to avoid the destructive interactions between (groups of) individuals who might experience conflicting priorities when either exploration or exploitation tasks are prioritized differently by them as part of their collaboration (De Clercq et al., 2013). Such "destructive interactions" will rapidly undermine the organization's ambition and the expected outcomes related to this ambition if they are not mitigated instantly.

2.1.3 Implementing contextual ambidexterity: enabling mechanisms. As clarified in the section above, the implementation of contextual ambidexterity represents a complex social phenomenon (Krogstrup, 2016). The appropriate orchestration of the employees and their knowledge and supportive processes are argued to be imperative to building an organizational culture and context that enable the requirements for the employees' ambidextrous work (Wang and Rafiq, 2014; O'Cass et al., 2014; Gaim and Wåhlin, 2016). Wang and Rafiq (2014, p. 71) argue the following:

[...] the implementation of contextual ambidexterity requires a fundamental change of management mentality, i.e., from the traditional top-down approach emphasizing the role of leadership and formal structure and governance (...) to a bottom-up learning approach recognizing the role of individual members in developing and shaping organizational culture and integrative capabilities of exploration and exploitation. 
If the implementation process is orchestrated appropriately, O'Cass et al. (2014, p. 863) claim that: Over time, capabilities will become embedded in organizational routines and processes. Hence, the literature expects that organizations can realize the beneficial outcomes/effects of the ambidextrous potential if they are successful with the implementation. There is still, however, scarce knowledge available about "how" contextual ambidexterity is created in practice. The foundation for a novel perspective to this "black box of ambidexterity" is provided below by presenting the theoretical background on organizational and individual capacity building.

\subsection{Individual and organizational capacity building}

Capacity building is a construct with many definitions and units of analysis, and as with many theoretical constructs, there is not any generally accepted standard (Honadle, 1981; Labin et al., 2012; Jensen and Krogstrup, 2017). As this manuscript is concerned with the organizational and individual perspective on capacity building, the stream of literature used for the conceptualization below is based on the work of Farazmand (2004), Ku and YuenTsang (2013), Labin et al. (2012), Jensen and Krogstrup (2017), and Krogstrup and Brix (2019). This stream of literature frames capacity building as an improvement process that focuses on the actions and interactions of an organization and its employees to seek their full potential (Honadle, 1981). Please see Figure 1 that attempts to illustrate the differences between the individual and the organizational levels of analysis in the capacity building construct.

According to Jensen and Krogstrup (2017), one of the difficulties in defining capacity building is based on the duality of the construct: Capacity building is both a process and an outcome. It is a process, because focus is on improving the existing capacities of the individuals. It is also an outcome because the capacities are improved as result of this capacity building process. Jensen and Krogstrup (2017, p. 2) define capacity building as: [...] the continuous enhancement of capabilities, but [capacity building] also concerns the building of the capacity to identify the need for further development as well as the need for new competences which may enable the formulation and achievement of own goals. Another definition that explicitly encompasses the individual and the organizational levels of analysis is provided by $\mathrm{Ku}$ and Yuen-Tsang (2013). They define capacity building as: Activities that strengthen the knowledge, abilities, skills and behavior of individuals, and improve institutional structure and processes, so that the organization can efficiently meet its goals in a sustainable way (Ku and Yuen-Tsang, 2013, p. 1). In addition to this, the capacity

Figure 1. Individual and organizational capacity building

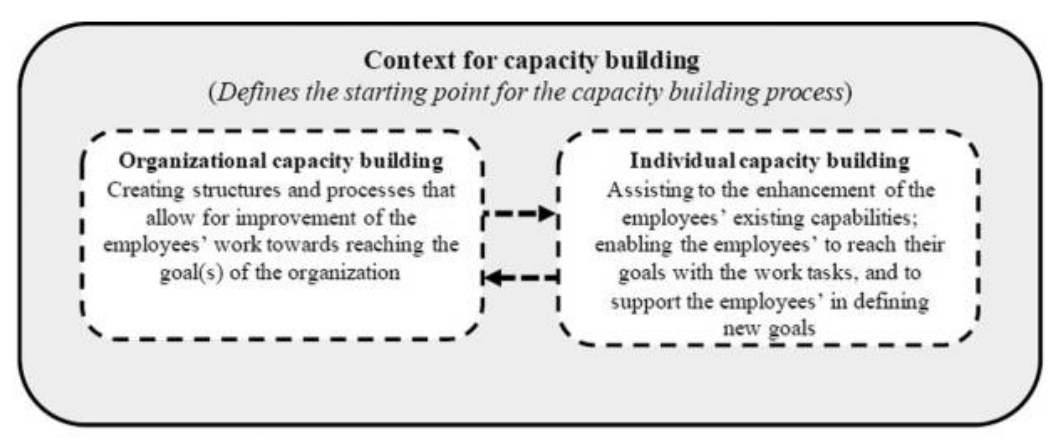

Source: Author's development 
building process is also context dependent. The argument is, that it is the existing capacities of the organization and its employees that define the strategies and activities that have to be realized to initiate and maintain relevant, local initiatives for improvement (Farazmand, 2004; Labin et al., 2012). This context dependency is illustrated by the outer frame of the individual and organizational processes to capacity building illustrated in Figure 1. The premise for the context dependency is further stressed by Jensen and Krogstrup (2017, p. 7): Changes are unlikely to succeed if the human conditions for this [capacity building] are not present in the organization and if all stakeholders do not develop negotiated ownership of the change. Capacity building thus has a temporal orientation towards the achievement of an improved future state. This implies that if one of the arrows between the individual and the organizational level of analysis in Figure 1 is not present, the capacity building process will not create the progress that is expected in the given context. Hence, it is imperative to stress that this dual level process to individual and organizational learning concerns both the organizational context for capacity building and a betterment of the individual employees' abilities to realize existing goals and define and frame new goals (Farazmand, 2004; Labin et al., 2012).

Table I is introduced to define and explain the many key constructs that are used in the following to unfold the capacity building research tradition utilized in this study.

2.2.1 Direct or indirect capacity building. In the literature, capacity building is divided into two modes of learning: the direct capacity building and the indirect capacity building (Krogstrup, 2016). Direct capacity building is about the formal professionalization of competencies that can be attained, such as by attending courses, following specialized master programs, by reading books and journals, or by seeking advice from external consultants. Direct capacity building hence represents a situation where there is an active or passive student-teacher dyadic relationship (Lane and Lubatkin, 1998). Indirect capacity building is best explained as 'learning by doing' (Krogstrup, 2016). In indirect capacity building, a specific initiative is defined, executed and assessed in such way that the output and the outcomes of the initiative are reflected upon. The learning stemming from this reflection can be utilized to redefine the initiative for delivering better performance in the next cycle (Labin et al., 2012). A top management team can hence provide access to 'direct capacity building' by investing in the employees' (and their own) formal competences and toolkits for the (new) job to be done (Farazmand, 2004). When the mandate is given to the employees so that they are enabled to execute the (new) job, "indirect capacity building" will emerge and determine "deceases" in the organization's culture, structure and processes that counteract the employees' new mandate (Farazmand, 2004). Identifying these counterproductive "deceases" will enable the management team and the employees to mitigate these, so a new attempt can be made to solve the task and increase the performance. The argument is that capacity building in this regard enables an organization and its member to: Cope with and manage ongoing current challenges (...) and to act well beyond by performing through anticipation, effective visions, proactive knowledge and skills, and self-corrective organizational behavior (Farazmand, 2004, p. 5). Related hereto, it is again emphasized that the ability and motivation for the employees to act on the potential opportunities for improvement or innovation is imperative, and that the managerial mandate to do so is present (Honadle, 1981). This dual focus is, according to Noya and Clarence (2009) and Jensen and Krogstrup (2017), solved through the capacity building literature's emphasis on empowerment. At this point, Figure 2 is introduced to complement the theoretical definitions presented in Table I. Figure 2 illustrates a hierarchy of these theoretical constructs, which have been - and which will - be discussed. 


\section{TLO}

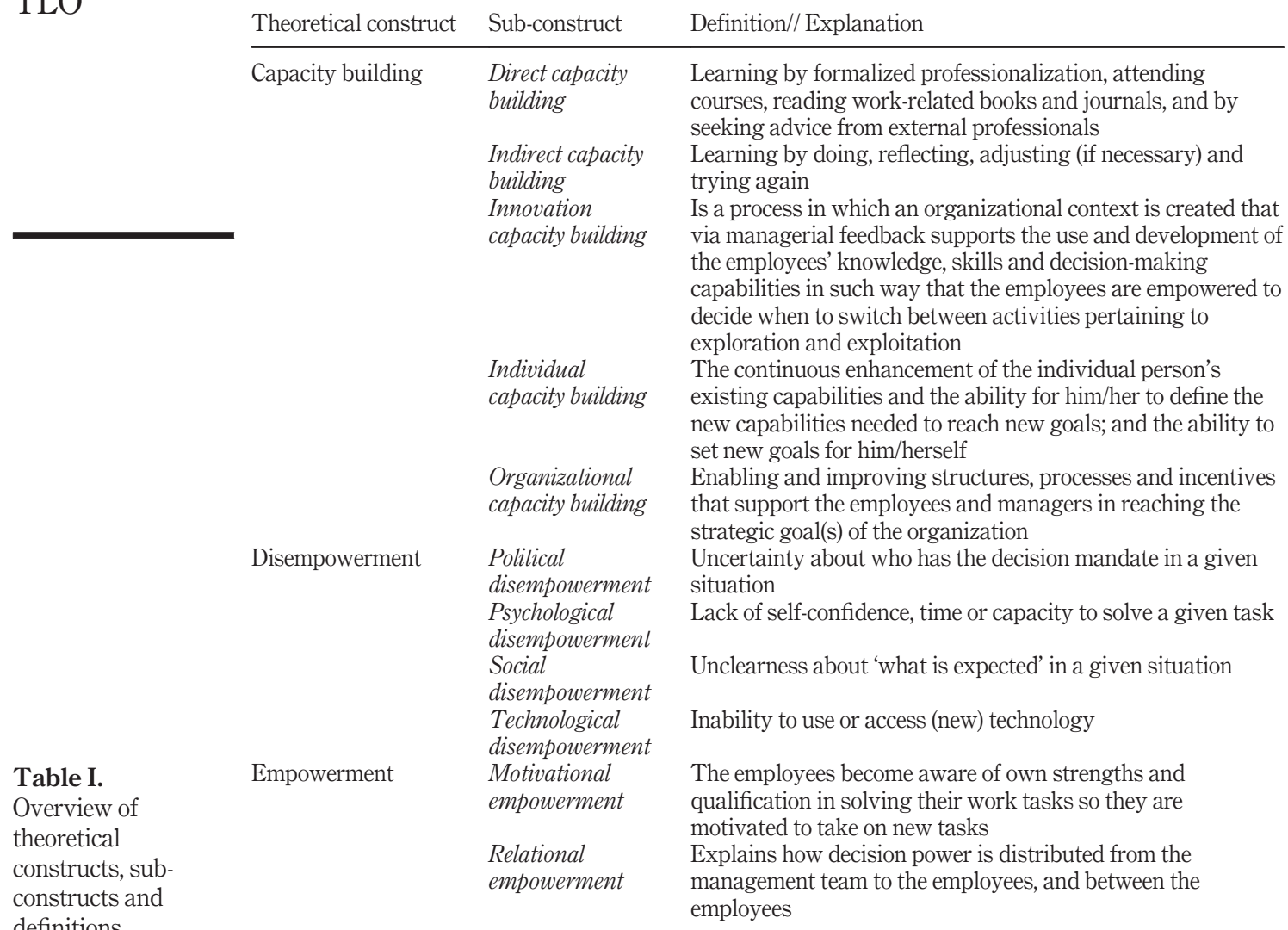

definitions (alphabetic order)

Source: Author's development

Figure 2.

An overview of theoretical constructs related to capacity building

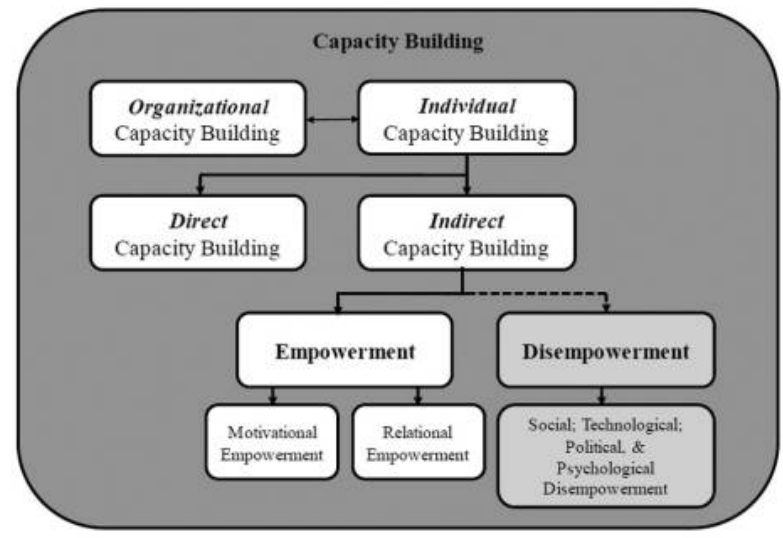

Source: Author's own development 
2.2.2 Empowerment-orientation in capacity building. Empowerment in relation to capacity building is, according to Krogstrup and Brix (2019), divided into two perspectives:

(1) a motivational perspective; and

(2) a relational perspective.

In the motivational perspective, the focus is on achieving a higher degree of self-awareness for the individual by identifying their skills and competencies and by improving these to create personal emancipation. In this perspective, the mandate to make decisions is also given to the individual to the extent that he/she has the capacity to take this mandate (Conger and Kanungo, 1988; Spreitzer, 1995; Fetterman et al., 2015). In the relational perspective, the collaborating actors' dependency to each other is in focus (Spreitzer, 1995). In this regard, the focus is on how power is distributed between the collaborating actors concerning decision-making. The empowerment perspective in capacity building thus establishes two important subcategories:

(1) the focus on the employees' motivation for achieving the organization's goal(s); and

(2) the division of the decision power from a managerial level to the employee level when the employees have the capacity to take this mandate.

2.2.3 Disempowerment. An important aspect of the empowerment-orientation is the notion of "disempowerment" (Lennie, 2005; Krogstrup and Brix, 2019). Disempowerment is a feeling of being unable to deliver or accomplish something that others expect one to do. According to Lennie (2005), there are multiple causes that lead to disempowerment, such as confusion about new initiatives (social disempowerment), the inability to utilize or access (new) technology (technological disempowerment), uncertainty about who has the actual decision mandate in project collaborations (political disempowerment), or the lack of confidence, time or capacity to solve the task at hand (psychological disempowerment) (Lennie, 2005). According to Krogstrup and Brix (2019), it is imperative that managers are aware of the potential disempowering mechanisms in the organizations before starting up new initiatives. If such mechanisms are identified, then managerial actions have to be made to correct or mitigate these mechanisms. In other words, if there are any disempowering mechanisms - which could have been illustrated as "dashed arrows" in Figure 1 - then the output and the outcome of the individual and organizational capacity building processes will not be reached (Krogstrup, 2016; Krogstrup and Brix, 2019). This introduction to the contextual ambidexterity literature and the literature on individual and organizational capacity building concludes the study's theoretical background. In the next section the two literatures are integrated to discuss the conceptualization of the "innovation capacity building" framework.

\section{Discussion and implications}

The chief argument for integrating the capacity building literature with the literature on contextual ambidexterity is one of unexplored complementarity: In the literature on contextual ambidexterity, little is known about the actual processes for creating an ambidextrous organizational culture (Raisch et al., 2009; Wang and Rafiq, 2014; Havermans et al., 2015), and in individual and organizational capacity building the context of ambidexterity has not been investigated (Farazmand, 2004; Jensen and Krogstrup, 2017; Krogstrup and Brix, 2019). It is argued that this complementarity can be achieved since both theoretical stances take a behavioral perspective to individual and organizational development, and they both emphasize the importance of the context's influence on the 
actual content and process that are to be implemented (Farazmand, 2004; Raisch et al., 2009; Wang and Rafiq, 2014; Jensen and Krogstrup, 2017).

In the following, arguments are made that provide claims for new theoretical insights based on the multilevel conceptualization of the innovation capacity building framework.

\subsection{What is 'innovation capacity building'?}

The working definition of "innovation capacity building" is as follows:

Innovation Capacity Building is a process in which an organizational context is created that via managerial feedback supports the use and development of the employees' knowledge, skills and decision-making capabilities in such a way that the employees are empowered to decide when to switch between activities pertaining to exploration and exploitation.

Innovation capacity building is thus framed as a proactive strategy (Krogstrup, 2016). In this strategy, the focus is on the feedback between managers and employees concerning how the organizational context, culture and leadership influence the actions and behaviors of the employees when switching between exploration and exploitation, and vice versa (Wang and Rafiq, 2014; Labin et al., 2012; O'Cass et al., 2014). The working definition lives up to the criteria for the successful implementation of contextual ambidexterity in practice claimed by Havermans et al. (2015), as a multilevel understanding of interactive processes between employees and their leaders is in focus (Andriopoulos and Lewis, 2009). These interactive processes are exemplified in the "how" sections of Figure 3.

Figure 3 is conceptualized in such way that it illustrates the "what" and the "how" of the relationship between the capacity building process on the organizational level, and the organizational level's connectedness to the process of individual capacity building and empowerment of the employees. In addition, the working definition makes explicit the process that defines: what capable organizations do (Honadle, 1981, p. 576) and it stresses that innovation capacity building is a: social product that is not produced by people, but in interaction between people (Krogstrup, 2016, p. 190). The goal of innovation capacity building is to continuously develop the organization and its employees in such way that the intended strategy can be realized. To enable this, focus is on utilizing existing knowledge and competencies as efficiently as possible, while simultaneously developing this

Figure 3.

The "innovation capacity building" framework

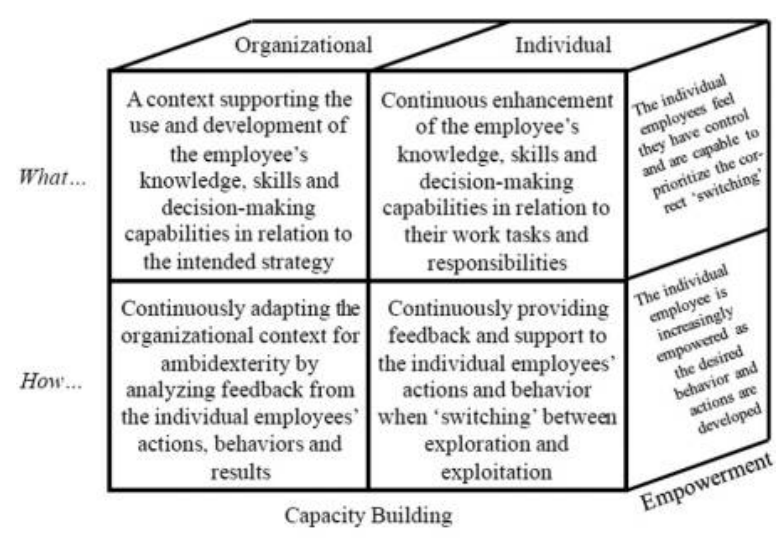

Source: Author's own development. Inspired by Krogstrup and Brix (2019) 
knowledge and these competencies so that new, smarter ways of working can be created (Farazmand, 2004; Ku and Yuen-Tsang, 2013; Jensen and Krogstrup, 2017). As reminder, this perspective is clarified in the "what" and "how" sections in Figure 3. Hence, innovation capacity building is claimed to be a process that enables the creation of contextual ambidexterity in existing organizations. In the following, this claim is examined by arguing how innovation capacity building can be achieved in a given context by discussing the new roles that are ascribed to the managers and the employees (Gibson and Birkinshaw, 2004; Wang and Rafiq, 2014).

\subsection{How is innovation capacity building achieved?}

Figure 4 below represents a simplified illustration of the transition from a non-ambidextrous organization towards an ambidextrous organization (the capacity building process). As a reminder, it is cf. Figure 1 emphasized that the capacity building process on an organizational and individual level is context dependent, and therefore focus in the following discussion is on the process of capacity building, not the content.

The role of the management is to enable the employees in accessing relevant "direct capacity building" initiatives related to their job. Remember that "direct capacity building" concerns e.g. formal professionalization initiatives, course work and reading work-related books and journals. Another important role of the management is to support the employees and to provide the employees with feedback concerning their "learning by doing" when they switch between work tasks related to exploration and exploitation. This feedback is illustrated by the learning loop arrows in Figure 4. It is - in other words - the management's job to focus on the importance of the "indirect capacity building" of the employees. As managerial feedback and the employees' own reflections on their "learning by doing" are used to improve the work processes, the individual employee can increase his/her sense of "motivational empowerment". As stated earlier, motivational empowerment refers to situations when an individual feels in control of his/her situation and capable of executing his/her job in a satisfying manner. In addition to this, the management can provide the employee with more decision power (relational empowerment) if (s)he feels ready to take on this mandate. These are the important (new) tasks of the managers in their new roles related to contextual ambidexterity.

The employees' role changes, as they become increasingly empowered to take (more) responsibility for acting ambidextrous than in organizations where structural or sequential

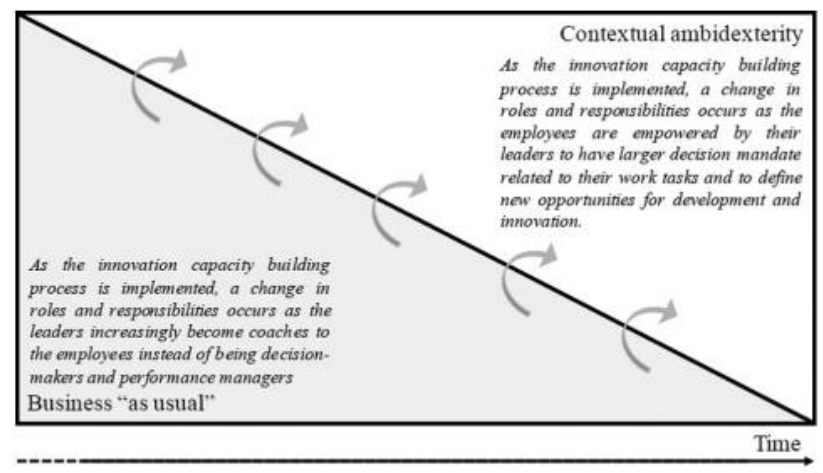

Source: Author's own development
Innovation capacity building 
ambidexterity is formalized top-down (Gibson and Birkinshaw, 2004). As contextual ambidexterity requires a bottom-up focus, it is important that the management does not expect that all employees feel capable of taking on this responsibility. An overnight decision to change the strategy might lead to confusion and hence the feeling of 'social disempowerment' and consequently counteract the initiative being implemented (Farazmand, 2004; Brix, 2015; Krogstrup and Brix, 2019). If this would happen then the good initiatives of the management would bounce back and the employee would require a more top-down-oriented decision making style, thus taking the value and advantages of contextual ambidexterity presented in Section 2.2.1 out of the implementation strategy.

When implementing the bottom-up strategy, "indirect capacity building" can be used as a mechanism over time to assess and provide feedback concerning the current state of the employees' motivation and competence to switch between exploration and exploitation. Reference is once again made to the feedback loops in Figure 4 that illustrates this situation. As the employees demonstrate positive behavior and self-reflective and self-corrective attitudes in their job, the management can empower the individual with a larger decision mandate (relational empowerment). This will take time, since contextual ambidexterity is argued to be a highly challenging work mode to implement in a non-ambidextrous organization (Gibson and Birkinshaw, 2004; Simsek, 2009; Gaim and Wåhlin, 2016). For the implementation to happen, reference is made to Figure 4 that explains the transition from "business as usual" towards an organization aiming at innovation capacity building. It is imperative that feedback and feedforward between managers and employees is given continuously throughout the organization so "acting ambidextrously" becomes a key part of the job descriptions, the work tasks and the organizational culture, and so "acting ambidextrously" does not only comprise the few selected innovation "champions" (O'Connor et al., 2018). Below concrete examples are illustrated of "how" content related to feedback and feedforward can be enabled between managers and employees.

3.2.1 Enabling feedback and self-corrective behavior. According to Honadle (1981), there needs to be a periodic assessment of 'what is being done' if the capacity building process is to be improved. Inspired by Honadle (1981, pp. 578-579), following examples illustrate practical questions that can be used to enable this assessment work in an organization that seeks to move from the left to the right side of Figure 4:

- “Are the employees' capacities to switch between exploration and exploitation adequate?"

- "Do barriers exist hindering the employees in the switching?"

- "Is the sheer amount of activity in relation to exploration and exploitation appropriate?", And

- "Could we be doing it better somehow?".

In addition to these questions, Honadle sets up a three step approach to operationalize the assessment work. First, one should monitor what the organization and its members are currently doing. Second, an evaluation of how well they appear to be doing it has to be made, and third, an assessment of whether the current level of effort is appropriate over time has to be done. These three steps and the questions pertaining to them could be implemented and act as mechanisms for knowledge creation concerning the "gaps" between existing organizational and individual capacities for contextual ambidexterity in a given organization. More importantly, the knowledge created via these steps could create the foundation for identifying the required changes to these organizational and individual capacities to build the foundation 
for a contextual ambidextrous organization (Farazmand, 2004; Simsek, 2009; Wang and Rafiq, 2014; Palm and Lilja, 2017) as an imperative part of the innovation capacity building process.

\section{Conclusion}

With the conceptualization of the innovation capacity building framework, this study discusses a concrete bottom-up approach to build and support a contextual ambidextrous organization. This conceptualization adds new theoretical insights to the research on contextual ambidexterity, which is scarcely represented in the organizational learning literature (Raisch et al., 2009; De Clercq et al., 2013; Wang and Rafiq, 2014; Havermans et al., 2015). More precisely, the innovation capacity building framework contributes to the existing research on organizational learning by explicitly linking the individual and organizational units of analysis from the capacity building research into the field of contextual ambidexterity with the explicit focus on the bottom-up approach (Wang and Rafiq, 2014). The innovation capacity building framework proposes how to enable the following: First, is suggests how to create a supportive, local context that, via direct capacity building, provides the employees with competences and tools to switch between explorative and exploitative activities. Second, it proposes how learning-oriented feedback and feedforward interactions can be made between the management team and the employees so the employees are empowered to use these (new) competencies and tools in practice. The argument is that this process will enable the employees to learn to take corrective actions and hence to improve their performance related to balancing between exploration and exploitation (indirect capacity building). Scholars and practitioners are invited to further develop and/or test the conceptualized framework both in public service organizations and in private enterprises where the quest for becoming an ambidextrous organization is on the strategic agenda.

\section{References}

Andriopoulos, C. and Lewis, M.W. (2009), "Exploitation-exploration tensions and organizational ambidexterity: managing paradoxes of innovation", Organization Science, Vol. 20 No. 4, pp. 696-717.

Benner, M.J. and Tushman, M.L. (2003), "Exploitation, exploration, and process management: the productivity dilemma revisited", Academy of Management Review, Vol. 28 No. 2, pp. $238-256$.

Brix, J. (2015), "Fail forward: mitigating failure in energy research and innovation", Energy Research and Social Science, Vol. 7, pp. 66-77.

Brix, J. (2017), "Exploring knowledge creation processes as a source of organizational learning: a longitudinal case study of a public innovation project", Scandinavian Journal of Management, Vol. 33 No. 2, pp. 113-127.

Brix, J. and Peters, L.S. (2015), "Exploring an innovation project as a source of change in organization design", Journal of Organization Design, Vol. 4 No. 1, pp. $29-43$.

Cegarra-Navarro, J.G. and Dewhurst, F. (2007), "Linking organizational learning and customer capital through an ambidexterity context: an empirical investigation in SMEs", The International Lournal of Human Resource Management, Vol. 18 No. 10, pp. 1720-1735.

Choi, T. and Chandler, S.M. (2015), "Exploration, exploitation, and public sector innovation: an organizational learning perspective for the public sector", Human Service Organizations: Management, Leadership and Governance, Vol. 39 No. 2, pp. 139-151.

Conger, J.A. and Kanungo, R.N. (1988), "The empowerment process: integrating theory and practice", Academv of Management Review, Vol. 13 No. 3, pp. 471-482. 
Crossan, M.M., Lane, H.W. and White, R.E. (1999), “An organizational learning framework: from intuition to institution", Academy of Management Review, Vol. 24 No. 3, pp. 522-537.

De Clercq, D., Thongpapanl, N.T. and Dimov, D. (2013), "Shedding new light on the relationship between contextual ambidexterity and firm performance: an investigation of internal contingencies", Technovation, Vol. 33 Nos 4/5, pp. 119-132.

Farazmand, A. (2004), "Innovation in strategic human resource management: building capacity in the age of globalization", Public Organization Review, Vol.4 No. 1, pp. 3-24.

Fetterman, D.M., Kaftarian, S.J. and Wandersman, A. (2015), Empowerment Evaluation: Knowledge and Tools for Self-Assessment, Evaluation Capacity Building, and Accountability, (2nd ed)., Thousand Oaks, CA.

Gaim, M. and Wåhlin, N. (2016), "In search of a creative space: a conceptual framework of synthesizing paradoxical tensions", Scandinavian Journal of Management, Vol. 32 No. 1, pp. 33-44.

Gibson, C.B. and Birkinshaw, J. (2004), "The antecedents, consequences, and mediating role of organizational ambidexterity", Academy of Management Journal, Vol. 47 No. 2, pp. 209-226.

Güttel, W.H. and Konlechner, S.W. (2009), "Continuously hanging by a thread: managing contextually ambidextrous organizations", Schmalenbach Business Review, Vol. 61 No. 2, pp. 150-172.

Havermans, L.A. D., Hartog, D.N., Keegan, A. and Uhl-Bien, M. (2015), "Exploring the role of leadership in enabling contextual ambidexterity", Human Resource Management, Vol. 54 No. 1, pp. 179-200.

Hoang, H.A. and Rothaermel, F.T. (2010), "Leveraging internal and external experience: exploration, exploitation, and R\&D project performance", Strategic Management Journal, Vol. 31 No. 7 , pp. 734-758.

Honadle, B.W. (1981), "A capacity-building framework: a search for concept and purpose”, Public Administration Review, Vol. 41 No. 5, pp. 575-580.

Huber, G.P. (2004), "The necessary nature of future firms: attributes of survivors in a changing world”, Sage Publications.

Jensen, J.B. and Krogstrup, H.K. (2017), Capacity Building in the Public Sector, Research Group for Capacity Building and Evaluation, Aalborg University, Denmark.

Krogstrup, H.K. (2016), Evalueringsmodeller, Udgave, Hans Reitzel. København, Vol. 3.

Krogstrup, H.K. and Brix, J. (2019), Co-Produktion i Den Offentlige Sektor, Brugerinvolvering I KVAlitetsudvikling, Hans Reitzels Forlag, København. ISBN: 9788741265384.

Ku, H.B. and Yuen-Tsang, A.W.K (2013), Capacity Building, in. Bevir, M. (ed.) The Sage Handbook of Governance, SAGE, USA, pp. 469-843.

Labin, S.N., Duffy, J.L., Meyers, D.C., Wandersman, A. and Lesesne, C.A. (2012), "A research synthesis of the evaluation capacity building literature”, American Journal of Evaluation, Vol. 33 No. 3, pp. 307-338.

Lane, P.J. and Lubatkin, M. (1998), "Relative absorptive capacity and interorganizational learning", Strategic Management Journal, Vol. 19 No. 5, pp. 461-477.

Lennie, J. (2005), "An evaluation capacity-building process for sustainable community IT initiatives: empowering and disempowering impacts", Evaluation, Vol. 11 No. 4, pp. 390-414.

March, J.G. (1991), "Exploration and exploitation in organizational learning", Organization Science, Vol. 2 No. 1, pp. 71-87.

Noya, A. and Clarence, E. (2009), "Community capacity building: fostering economic and social resilience", Organisation for Economic Cooperation and Development, pp. 26-27.

O'Cass, A., Heirati, N. and Ngo, L.V. (2014), "Achieving new product success via the synchronization of exploration and exploitation across multiple levels and functional areas", Industrial Marketing Management, Vol. 43 No. 5, pp. 862-872.

O'Connor, G.C., Corbett, A. and Peters, L.S. (2018), Beyond the Champion: Institutionalizing Innovation through People, Stanford University Press, USA. 
O'Reilly, C.A. and Tushman, M.L. (2013), "Organizational ambidexterity: past, present, and future”, The Academy of Management Perspectives, Vol. 27 No. 4, pp. 324-338.

Palm, K. and Lilja, J. (2017), "Key enabling factors for organizational ambidexterity in the public sector", International Journal of Quality and Service Sciences, Vol. 9 No. 1, pp. 2-20.

Innovation capacity building

Raisch, S., Birkinshaw, J., Probst, G. and Tushman, M.L. (2009), "Organizational ambidexterity: balancing exploitation and exploration for sustained performance", Organization Science, Vol. 20 No. 4, pp. 685-695.

Simsek, Z. (2009), "Organizational ambidexterity: towards a multilevel understanding”, Journal of Management Studies, Vol. 46 No. 4, pp. 597-624.

Simsek, Z., Heavey, C., Veiga, J.F. and Souder, D. (2009), "A typology for aligning organizational ambidexterity's conceptualizations, antecedents, and outcomes", Journal of Management Studies, Vol. 46 No. 5, pp. 864-894.

Sirmon, D.G., Hitt, M.A., Ireland, R.D. and Gilbert, B.A. (2011), "Resource orchestration to create competitive advantage: breadth, depth, and life cycle effects", Journal of Management, Vol. 37 No. 5, pp. 1390-1412.

Smith, W.K. and Tushman, M.L. (2005), "Managing strategic contradictions: a top management model for managing innovation streams", Organization Science, Vol. 16 No. 5, pp. 522-536.

Spreitzer, G.M. (1995), "Psychological empowerment in the workplace: dimensions, measurement, and validation", Academy of Management Journal, Vol. 38 No. 5, pp. 1442-1465.

Uotila, J., Maula, M., Keil, T. and Zahra, S.A. (2009), "Exploration, exploitation, and financial performance: analysis of S\&P 500 corporations", Strategic Management Journal, Vol. 30 No. 2, pp. 221-231.

Wang, C.L. and Rafiq, M. (2014), "Ambidextrous organizational culture, contextual ambidexterity and new product innovation: a comparative study of UK and chinese high-tech firms", British Journal of Management, Vol. 25 No. 1, pp. 58-76."

Wei, Z., Yi, Y. and Guo, H. (2014), "Organizational learning ambidexterity, strategic flexibility, and new product development”, Journal of Product Innovation Management, Vol. 31 No. 4, pp. 832-847.

Yang, H. and Atuahene-Gima, K. (2007), "Ambidexterity in product innovation management: the direct and contingent effects on product development performance", Paper Presented at the Annual Meeting of the Academy of Management, Philadelphia, PA.

\begin{abstract}
About the author
Jacob Brix is Associate Professor of innovation and organizational learning at Aalborg University's Department of Learning and Philosophy. He is member of the "Research Group for Capacity Building and Evaluation" (CABE) and he is enrolled in the Faculty's talent program in social science. In addition to this, Jacob has had an ongoing visiting scholarship at the "Lally School of Management" at Rensselaer Polytechnic Institute in Troy, New York since 2012. Jacob Brix can be contacted at: brix@learning.aau.dk
\end{abstract}

For instructions on how to order reprints of this article, please visit our website: www.emeraldgrouppublishing.com/licensing/reprints.htm Or contact us for further details: permissions@emeraldinsight.com 